\title{
Uma análise interpretativa do Ponteio no 30 de Camargo Guarnieri
}

\section{Nathalia Freitas Leite}

Resumo: O presente trabalho é parte de uma pesquisa de mestrado em andamento e tem a finalidade de apresentar resultados parciais por meio da reflexão sobre aspectos interpretativos do Ponteio $\mathrm{n}^{\circ} 30$ do compositor Camargo Guarnieri através da análise da obra. Foi empregado o método de análise compreensiva de John White. Indícios sobre o estilo do compositor foram encontrados principalmente em depoimentos de músicos e estudiosos. Como conclusão, pretende-se apresentar sugestões interpretativas ao leitor, contribuir para a pesquisa acadêmica na área, colaborando para a divulgação da obra do compositor e para alargamento da bibliografia existente.

Abstract: The present paper is part of an ongoing research at graduate level (Master program) which purpose is showing partial results of the author's analytical investigation regarding interpretative aspects of the Ponteio $n^{0} 30$ by composer Camargo Guarnieri. John White's comprehensive analysis method was employed. Clues about the composer style were found mainly in testimonials of musicians and scholars. By means of this interpretative approach, we hope to contribute to the academic research which combines analysis and performance, disseminating as well the work of this composer and to broaden the existing bibliography.

\section{Introdução}

Durante o processo de elaboração da interpretação musical de qualquer obra, somos levados a fazer escolhas interpretativas que comporão a realização da performance, que serão guiadas pela apreensão das características composicionais da obra e reconhecimento do estilo do compositor. Portanto, o objetivo deste trabalho é encontrar, 
através da análise, dados relevantes que podem ser considerados durante a elaboração e execução de uma performance, para que, a partir da compreensão do texto musical, seja alcançada uma interpretação próxima das características próprias pertinentes à música brasileira.

\section{Considerações sobre estilo}

O musicólogo e compositor russo Boris Asafyev afirma que o que constitui o caráter nacional é sua entonação (Dahlhaus, 1989, p. 38). Com isso em mente, buscamos na bibliografia algumas referências as características da música brasileira e diversas vezes encontramos palavras como relaxado, seresteiro e maleável para descrever o caráter da música brasileira. José Ramos Tinhorão, falando sobre o surgimento do samba-canção, afirma que o "modo dolente de interpretar o que se entendia então por canção permitira aos compositores da época reduzir vários ritmos (num fenômeno semelhante ao ocorrido com o choro) a uma massa sonora caracteristicamente brasileira e carioca (...)" (Tinhorão, 2012, p. 57). Cacá Machado reforça a ideia do caráter relaxado ao falar sobre a adaptação da polca europeia no território brasileiro: "(...) a partir da década de 1870 , pode-se identificar um processo de adaptação da polca europeia, mais marcial e tônica, para uma polca mais relaxada e sincopada - uma polca recriada em solo nacional." (Moraes, Saliba, 2010, p. 127).

A partir desses autores, podemos concluir, então, que a música brasileira teria, uma entonação mais maleável, relaxada, sincopada, coreográfica até. No Ensaio sobre a musica brasileira Mario de Andrade fala extensamente sobre a adequação da síncopa brasileira, na qual melodia se desenvolve livremente pelo tempo sem necessariamente coincidir com o compasso; ela é para fora do compasso. Portanto podemos dizer que essa maleabilidade faz o tempo na música brasileira ser um tempo mais livre e psicológico e não estritamente cronológico. 


\section{Análise Compreensiva}

Para a performance, um dos resultados importantes da análise musical é entender o estilo musical da obra, do compositor ou do período. Além disso, a compreensão da estrutura, da organização, dos pontos de tensão e relaxamento e da expressividade intrínseca à obra passa pela análise. E essa compreensão é o que vai guiar as escolhas do performer a criar uma interpretação expressiva e apropriada. Para a análise do ponteio deste trabalho foi usado o método de análise compreensiva de John White, que se encontra em seu livro Comprehensive Music Analysis.

Em sua análise compreensiva, White divide o processo em duas partes: Passo 1 - Análise descritiva, na qual são analisadas todas as características composicionais da obra, e Passo 2 - Síntese e conclusões, o momento no qual todos esses dados coletados são interpretados e resignificados a fim de compreender questões estéticas e estilísticas da obra e do compositor.

\section{Análise do Ponteio $n^{\circ} 30$}

O Ponteio n.30 - Sentido foi composto por Camargo Guarnieri em 1955 e faz parte do terceiro caderno de ponteios do compositor. Os ponteios são considerados por alguns músicos e estudiosos uma das joias da música brasileira, que expressam com sentimento a "alma musical do povo" (Verhaalen, 2001, p. 128.). Segundo Belkiss Carneiro de Mendonça, os ponteios de Guarnieri "são quadros significativos, que reproduzem imagens da maneira de ser e de sentir do povo brasileiro" (Mendonça, 2001, p. 402, 404). Para João Caldeira Filho, "Guarnieri vive em clima de constante disponibilidade ao emotivo, de contemplação das suas paisagens interiores" (Filho, 2001, p.17-18), e nas palavras do próprio Guarnieri, "música é emoção" (Filho, 2001, p. 18). Dessa forma, 
não é de se espantar que todos os 50 ponteios do compositor indicam logo acima do primeiro compasso não um andamento, e sim um estado de espírito.

Entre a grande variedade de caráter e expressões retratadas por Guarnieri - calmo, gingado, dolente, animado, decidido e outros Francisco Curt Lange afirma que "o rubato interno encontrado com tanta frequência na música brasileira" (Verhaalen, 2001, P. 129) é algo que todos os ponteios do compositor têm em comum. Esse rubato pode ser caracterizado de diversas formas, e no Ponteio n.30 ele é sugerido principalmente pelo tema levemente sincopado que percorre toda a obra.

Apesar de ser em compasso binário, o segundo tempo do compasso é constantemente enfatizado. Essa ênfase é dada por quatro fatores: (1) uso da dinâmica (crescendo em direção ao segundo tempo), (2) frequente uso de pausas no primeiro tempo dos compassos, (3) indicação de acentos (>) no segundo tempo e (4) utilização de semínimas pontuadas que se contrapõem ao resto da melodia, composta apenas por colcheias. A frase melódica, que será reiterada repetidamente pela obra, é formada pelo motivo gerador (apresentado no primeiro compasso) e sua variação. Esse motivo é caracterizado por descrever o arco de uma tríade descendente seguido de um salto ascendente (quase sempre de $6^{\text {a }}$ ou $7^{\mathrm{a}}$ ) oitavado, acentuado $(>$ ) e em nota mais longa, terminando em um intervalo de segunda descendente, formando uma grande apojatura expressiva (Ex. 1). 
Exemplo 1: Compassos 1, 3, 6 e 10.

Compasso 1

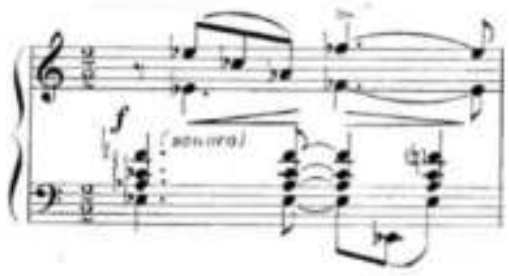

Compasso 6

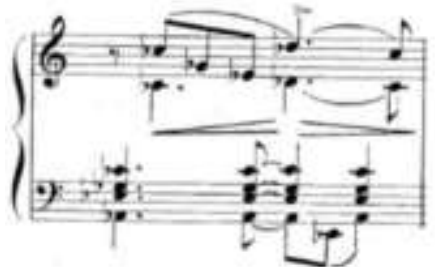

Compasso 3

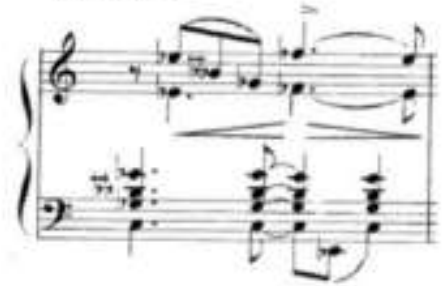

Compasso 10

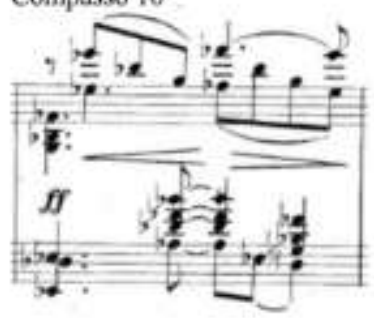

Aqui a afirmação de Mario de Andrade que "a nossa melódica afeiçoa as frases descendentes" (Andrade, 1928, p. 37) encontra respaldo tanto na primeira quanto na segunda parte da frase, que é uma variação do primeiro motivo e na qual a melodia realiza movimentos em oitavas descendentes, que nos remete a melodias chorosas encontradas nos choros e canções da música tradicional brasileira (Ex. 2).

Exemplo 2: Compassos 1-2, primeira frase melódica

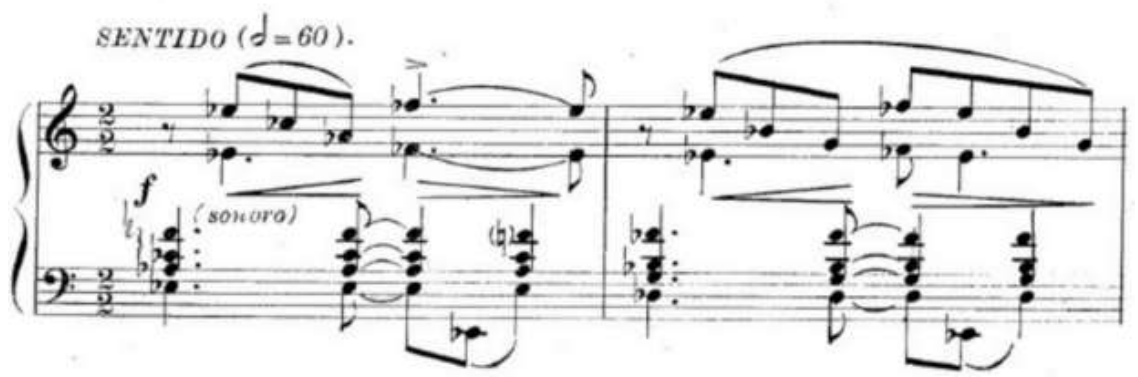


A parte rítmica do ponteio é pouco contrastante: o ritmo é estável por toda a obra, pois é repetitivo e possui pouca variação das figuras, onde o elemento sincopado é constante, com a predominância de colcheias que formam o motivo. A textura sonora também não apresenta grandes contrastes: é quase sempre ampla e densa, mostrando momentos com até oito notas ao mesmo tempo (grandes acordes) ocupando uma tessitura ampla do piano e propiciando uma ampla ressonância. Apesar do timbre quase sempre estável, a partir do compasso 26 há uma mudança importante na sonoridade: $p$ subito precedido de cezura em $f f$, as mãos cruzam (a melodia vai para a região grave) e a amplitude da tessitura, que até alguns compassos antes ultrapassava quatro oitavas, diminui para menos de duas oitavas (Ex. 3).

Exemplo 3: Compassos 24-26.

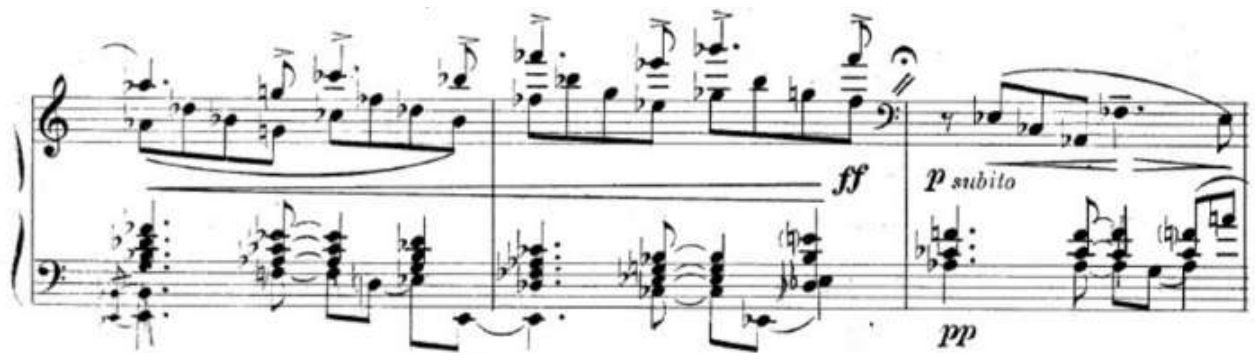

A textura só vai voltar à sua tessitura inicial de três oitavas a partir do compasso 35, na última apresentação do tema, porém em $p$ e poco meno. O ponteio termina em calmando e diminuendo. (Ex. 4) consideravelmente diferente do começo da obra, que apresenta o tema em $f f$ e sonoro, portanto com outra atmosfera e outro humor.

No livro Camargo Guarnieri: O tempo e a música, Belkiss Carneiro de Mendonça escreve:

"No $n^{\circ} 30$, 'Sentido', a melodia sonora e apaixonada vem apoiada em harmonia rica, com acordes cromáticos em posição afastada. Camargo Guarnieri procurou retratar uma cena presenciada num 
botequim, quando um mulato alcoolizado cantava, com acentos apaixonados, um samba carioca, acompanhando-se ao violão." (Mendonça, 2001, p. 404, 405).

Não é indicada no livro a procedência dessa informação. Mas concordamos que o ponteio apresenta um tema melancólico, apaixonado, e como o próprio Guarnieri indicou: sentido. Pode-se dizer que é um sentido lamentoso, doído até, que suplica a cada vez que enfatiza o segundo tempo sustentado pela apojatura e soluça a cada pausa no primeiro tempo. A partir do compasso 10 a lamentação fica mais apaixonada e intensa ( $f f$, aumento da textura sonora e da amplitude usada no piano). Subitamente, esses soluços interrompidos se transformam em um outro motivo, ainda com algumas semelhanças com o primeiro, porém mais simples e repetitivo. (Ex. 5).

Exemplo 4: Compassos 33-41.
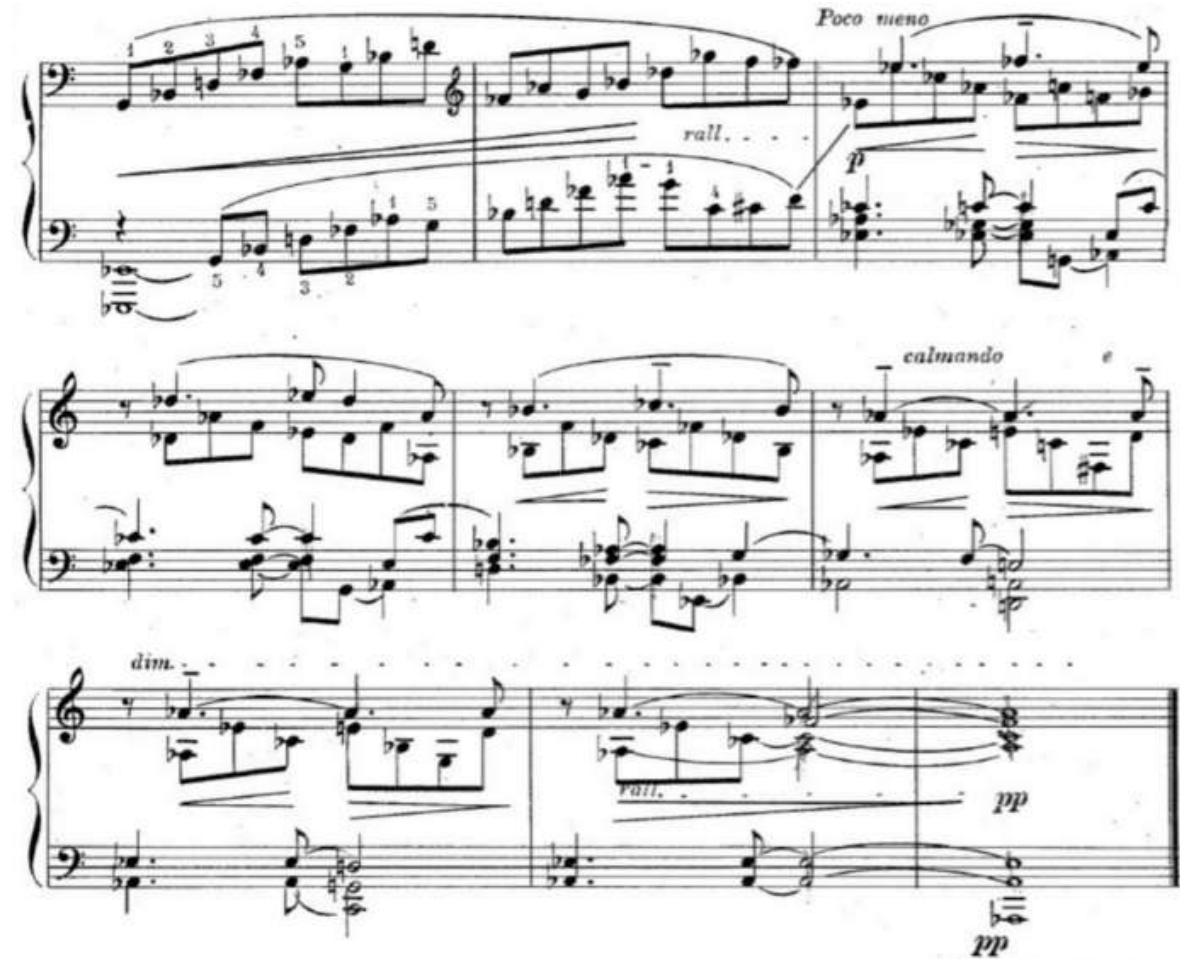


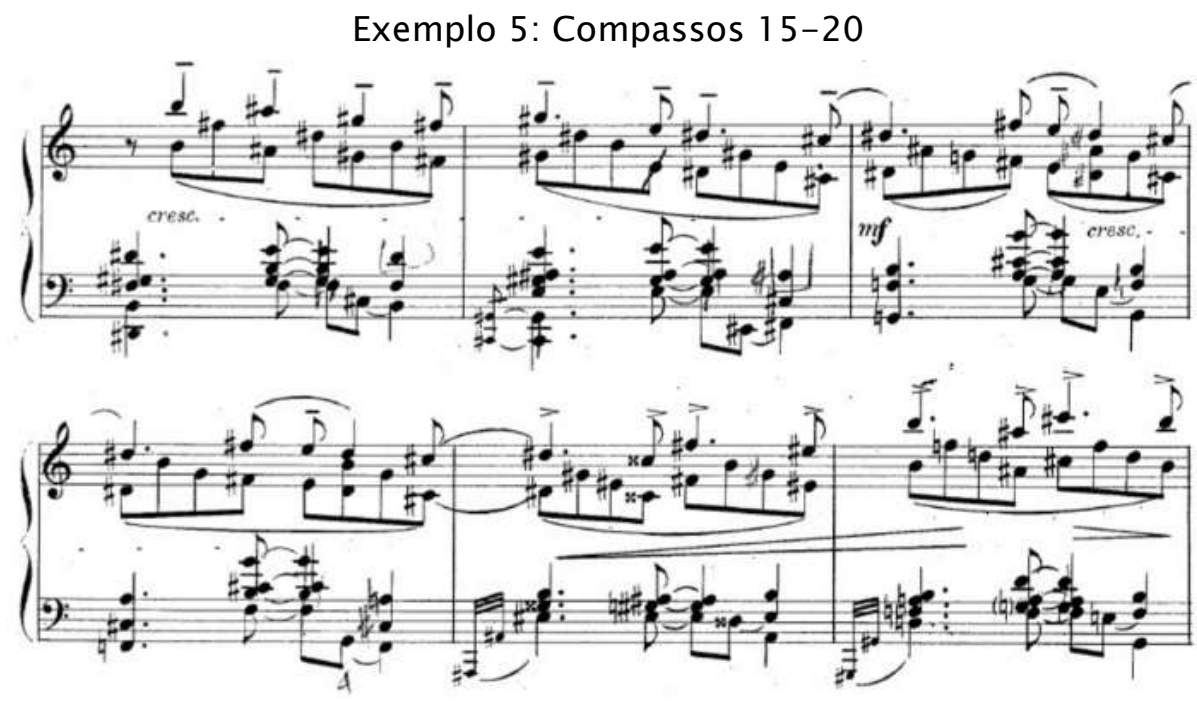

Esse segundo motivo vai se tornando mais urgente e expansivo conforme se aproxima do seu final, crescendo em dinâmica, textura sonora e subindo no registro do piano. Ele atinge seu ápice no compasso 25 , com a nota mais aguda da obra e é interrompido abruptamente no final desse compasso com uma cezura, sem nenhuma cadência ou qualquer resolução harmônica, deixando no ar por alguns segundos uma sensação de grande tensão e incerteza construída pelos compassos anteriores (Ex. 3).

Após essa grande suspensão, o tema principal volta, porém dessa vez mais reflexivo, sombrio, em uma região mais grave do que a apresentada anteriormente e com as duas mãos cruzadas. Aqui a voz intermediária tocada pela mão esquerda mostra pequenas intervenções, como comentários que colaboram em curto diálogo com o tema (Fig. 6). 
Exemplo 6: Compassos 26-29.

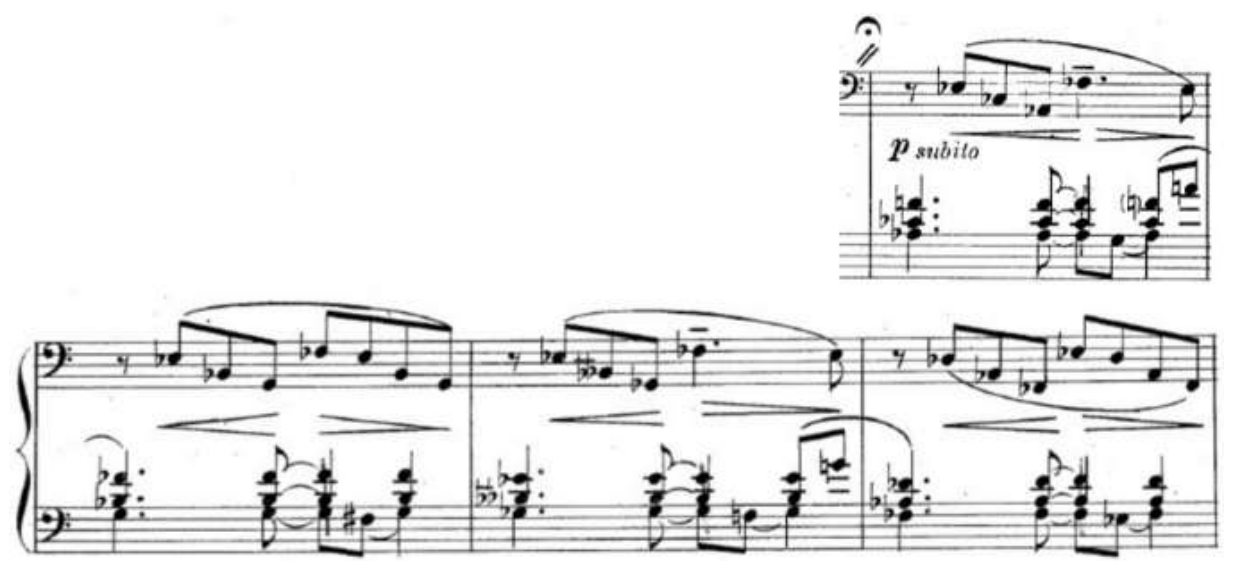

O tema se repete pela ultima vez na região mais aguda a partir do compasso 35, agora poco meno e em $p$. Cansado de cantar seu queixume ou talvez mais melancólico por não encontrar solução para sua dor, o tema vai morrendo aos poucos, ficando cada vez com menos notas até parar de vez, sempre rall. e dim. (Ex. 7).

Exemplo 7: Compassos 36-41.
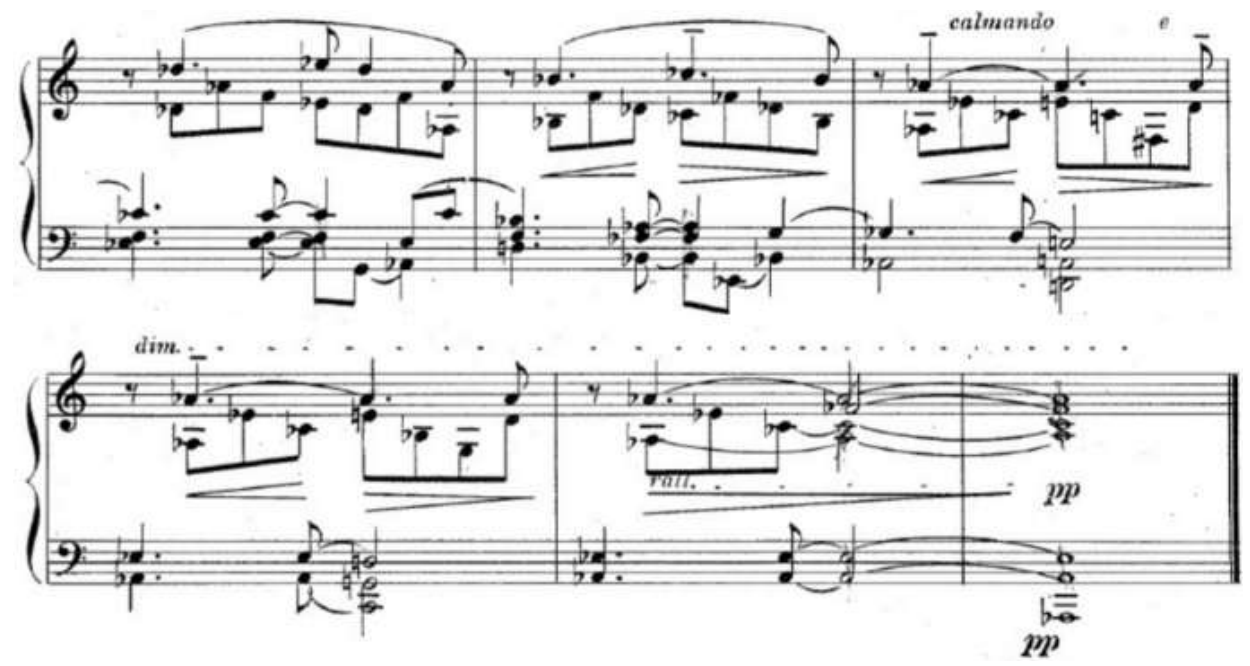
Ao analisar a harmonia, percebe-se que a obra é consideravelmente dissonante, com muitos acordes acrescidos de $9^{\mathrm{a}} \mathrm{s}$ e $7^{\mathrm{a}} \mathrm{s}$, alguns com $6^{\mathrm{a}}$, uma $8^{\mathrm{a}}$ aumentada e uma $8^{\mathrm{a}}$ diminuta, além de tríades e tétrades diminutas. O caminho harmônico não é de nenhuma forma óbvio, porém em um momento foi usado um acorde maior imediatamente repetido em seu modo menor, e em dois outros momentos um acorde menor repetido como diminuto (Ex. 8).

Exemplo 8: Compassos 4 e 5; 13 e 14; 29 e 30.

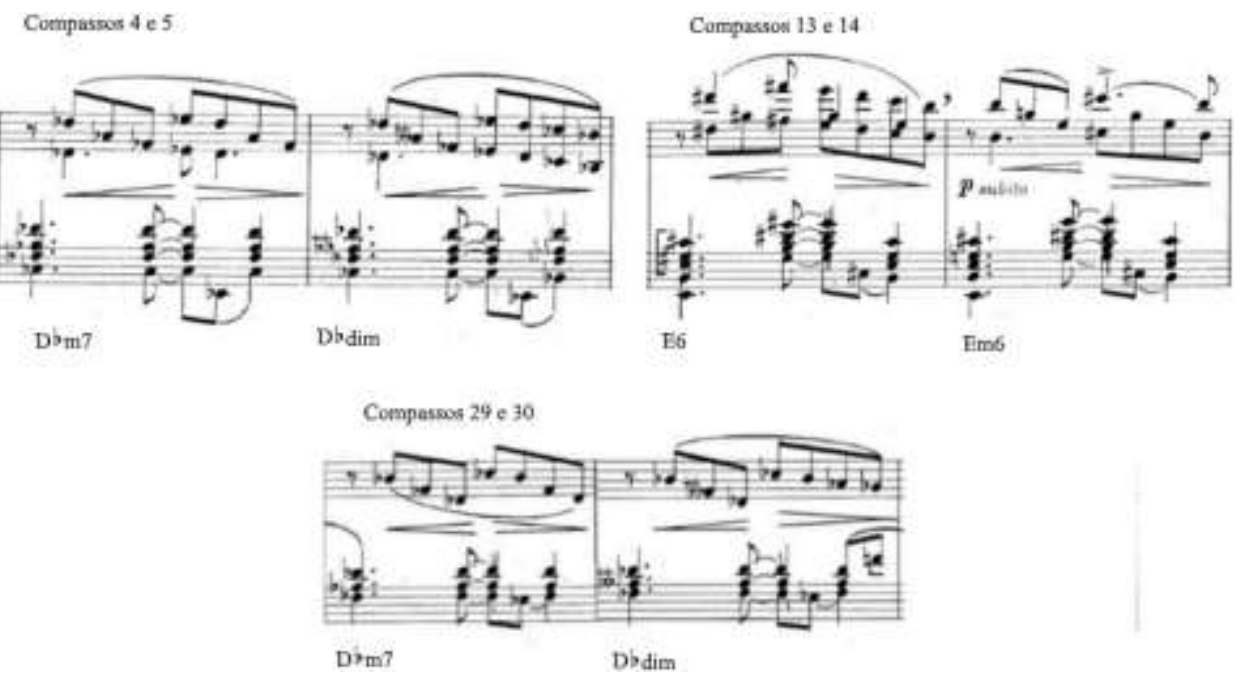

Este é um recurso que já foi largamente utilizado por muitos compositores de diversos períodos da história, funcionando muitas vezes como recurso expressivo. Um desses momentos foi enfatizado pelo próprio compositor, com um corte abrupto (respiração) em dinâmica $f f$ seguido de $p$ subito. Esse tipo de contraste dinâmico aparecerá novamente na cezura do compasso 26 , na qual o tema principal é reapresentado. 


\section{Sugestões finais}

Esta é apenas uma interpretação, e, por interpretações serem abertas, várias são possíveis. Porém aliando a análise da obra ao conhecimento do estilo da época e do compositor, foi possível elaborar algumas escolhas interpretativas que achamos adequadas. O ponteio analisado não possui grandes contrastes de ritmo nem de material melódico - os maiores contrastes se encontram no âmbito da harmonia e da dinâmica. Como bem colocou Belkiss Carneiro de Mendonça, a harmonia é rica e apresenta sequencias de acordes cromáticos, portanto harmonicamente distantes, e em posição afastada, ampliando sua sonoridade. Sugere-se que o intérprete dê atenção aos contrastes harmônicos e dinâmicos, explorando suas possibilidades timbrísticas, que se preocupe em criar sonoridades variadas para os diferentes momentos emocionais da obra, dentro de uma maleabilidade rítmica apresentada pelas sincopas presentes, promovendo, assim, a dramaticidade necessária na leitura do ponteio.

\section{Referências}

ANDRADE, Mario de. Ensaio sobre a música brasileira. $4^{\mathrm{a}} \mathrm{Ed}$. Belo Horizonte: Editora Itatiaia, 1928.

DAHLHAUS, Carl. Nineteenth Century Music. California: University of California Press, 1989.

FILHO, João Caldeira. Camargo Guarnieri - uma trajetória. In: SILVA, Flávio (Org.). Camargo Guarnieri: o tempo e a música. Rio de Janeiro: Funarte, 2001. P. 17-19.

GUARNIERI, Camargo. Ponteio $n^{\circ} 30$. São Paulo: Ricordi, 1970, composto em 1955.

MENDONÇA, Belkiss Carneiro de. A obra pianística. In: SILVA, Flávio (Org.). Camargo Guarnieri: o tempo e a música. Rio de Janeiro: Funarte, 2001. P. $401-422$. 
MORAES, José Geraldo Vinci de; SALIBA, Elias Thomé. História e música no Brasil. São Paulo: Alameda, 2010.

TINHORÃO, José Ramos. Música popular. um tema em debate. $4^{\mathrm{a}}$ Ed. São Paulo: Editora 34, 2012.

VERHAALEN, Marion. Camargo Guarnieri: expressões de uma vida. São Paulo: Editora da Universidade de São Paulo/Imprensa Oficial, 2001. WHITE, John D. Comprehensive Music Analysis. London: The Scarecrow Press, 1994. 